\title{
Yos Sebagai Pengintegrasian Masyarakat Desa Pedawa
}

\author{
Ni Putu Arik Febriani*, I Wayan Suwena, Aliffiati \\ Program studi Antropologi, Fakultas Ilmu Budaya, Unud \\ Email: ptanikfebriani@gmail.com \\ Gianyar, Bali, Indonesia \\ *Corresponding Author
}

\begin{abstract}
Pedawa Village community, Banjar sub-district, Buleleng Regency has two kawitan namely kulit and kawitan lokal. Kawitan kulit that found in Pedawa Village is the general kawitan in Bali, meanwhile kawitan local of the Pedawa Village community refers to Yos which must be owned by all Pedawa Village communities. The Yos has a highly glorified God and the god closest to the community because the God is believed to be a protective deity, with the existence of the Yos the formation of social class in society. This reserach aimed to know the status and role of community members based on Yos, and to reveal the implications of Yos for the social structure of the Pedawa Village community. The results of the study revealed that there were 14 types of Yos. From several types of Yos, there are several members of community who have the status and role in a ceremony namely as Balian Desa, Premas, Headman, Janbangul, Pedewasan, and Sekaa Gong. Yos also has important implications and meanings toward the Pedawa Village community. The implications of Yos on aspects of the pedawa Village community belief system, besides the implications there are also meanings of Yos covering religious meaning, social meaning and cultural meaning.
\end{abstract}

Keywords: Yos, integration, and status

\begin{abstract}
Abstrak
Masyarakat Desa Pedawa, Kecamatan Banjar, Kabupaten Buleleng memiliki dua kawitan yaitu kawitan kulit dan kawitan lokal. Kawitan kulit merupakan kawitan pada umumnya di Bali, sedangkan kawitan lokal masyarakat Desa Pedawa menyebut dengan "Yos" yang wajib dimiliki oleh semua masyarakat. Yos tersebut terdapat dewa yang sangat dimuliakan dan dewa yang paling dekat dengan masyarakat karena dewa tersebut dipercayai sebagai dewa pelindung, dengan adanya Yos tersebut maka terbentuknya kelas sosial dalam masyarakat. Adapun tujuannya ialah untuk mengetahui status dan peran anggota masyarakat berdasarkan Yos, dan untuk mengungkap implikasi Yos dalam struktur sosial masyarakat Desa Pedawa.Hasil penelitian mengungkapkan bahwa ada 14 macam Yos. Dari macam-macam Yos tersebut terdapat beberapa anggota masyarakat yang memliki status dan peran dalam suatu upacara yaitu berperan sebagai Balian Desa, Premas, Kepala Desa, Janbangul, Pedewasan, dan Sekaa Gong. Adapun implikasi dari Yos yaitu implikasi Yos terhadap kehidupan dalam keluarga dan masyarakat, implikasi Yos pada aspek sistem kepercayaan masyarakat, selain implikasi terdapat juga makna dari Yos meliputi makna religi, makna sosial, dan makna budaya.
\end{abstract}

Kata Kunci :Yos, integrasi, dan status 


\section{PENDAHULUAN}

Bali merupakan salah satu provinsi yang ada di Indonesia, sangat kental dengan hukum adat dan kebiasaankebiasaan yang berlaku dalam masyarakat adat yang ditunjukkan untuk mengatur kebutuhan masyarakatnya (Kadek Andre Hendrawan dan Putu Sugi Ardana, 2018: 1). Lokalitas dalam suatu wilayah tidak dapat terlepas dari sistem yang diberlakukan di dalam aspek kehidupan masyarakatnya.Salah satunya adalah sistem kekerabatan di dalam struktur masyarakat (Sari, 2015: 1). Kelompok kekerabatan masyarakat Bali dikenal dengan istilah dadia, yang merupakan gabungan dari keluarga luas patrilineal yang tinggal dalam satu pekarangan. Fungsi yang paling utama dari dadia adalah melakukan usaha produktif dalam bidang ekonomi, memelihara hubungan tolong-menolong dalam kegiatan-kegiatan sosial-budaya maupun politik. Ikatan kekerabatan dalam masyarakat Bali saat ini masih dikatakan cukup kuat. Mereka yang berasal dari kerabat yang sama (tunggal dadia) memiliki hubungan sosial yang sangat kuat (Geriya, 2000: 116).

Masyarakat Hindu Bali mengenal kelompok kekerabatan soroh kawitan, yang merupakan asal mula atau leluhur seseorang yang menjadi cikal bakal keberadaan keluarganya di masa kini atau bisa dikatakan bahwa kawitan adalah asal mula sebuah soroh atau clan yang ada di Bali. Secara universal, di Bali hanya mengenal satu kawitan, tetapi menariknya di Desa Pedawa mengenal dua kawitan yaitu kawitan kulit dan kawitan lokal.

Desa Pedawa, Kecamatan Banjar, Kabupaten Buleleng merupakan salah satu Desa Bali Aga yang ada di Bali Utara. Letak Desa Pedawa berdampingn dengan empat desa Bali Aga yang lain, yaitu Desa Sidetapa, Cempaga, Tigawasa, dan Banyuseri (Mayuko,
2015: 5). Desa Pedawa yang merupakan salah satu desa tua yang mempunyai keunikan tersendiri dibandingkan dengan desa lain selain desa Bali Aga yang ada di Bali. Keunikan dari segi bahasa maupun ritual keagamaan yang kental yang menjadikan Desa Pedawa ini sangat unik (Putu Edy Suryadi Yasa, dkk, 2017: 3). Desa Pedawa ini tidak mengenal sistem kasta (wangsa) seperti di Bali umumnya. Semua masyarakat di sana memiliki kedudukan yang setara. Masyarakat hanya mengenal istilah tetua desa, yang dipilih secara tidak langsung oleh masyarakat desa. Sistem kekeluargaan seperti masyarakat Bali pada umumnya hanya mengenal sistem patrilineal. Dalam sistem kekerabatan ini, kedudukan anak laki-laki sangat penting baik di dalam keluarga maupun di dalam Pura (Ariawan dkk, 2018: 5).

Masyarakat Desa Pedawa mengenal dua kawitan, yaitu kawitan kulit dan kawitan lokal.Kawitan kulit merupakan asal mula atau leluhur seseorang yang menjadi cikal bakal keberadaan keluarganya di masa kini. Sedangkan, kawitan lokal masyarakat Desa Pedawa menyebut dengan "Yos" yang wajib dimiliki oleh semua masyarakat Desa Pedawa.

Yos merupakan kelompok-kelompok kekerabatan karena di dalam Yos tersebut terdapat keluarga inti yang terdiri dari seorang suami, seorang istri, dan anakanak mereka yang belum kawin. Mengenai kelompok-kelompok kekerabatan, ada tiga kategori kelompok kekerabatan yang sebenarnya menyangkut fungsi-fungsi sosial dari kelompok-kelompok kekerabatan, yaitu: kelompok kekerabatan berkorporasi (corporate kingroups), kelompok kekerabatan kadangkala (occasional kingroup), dan kelompok kekerabatan menurut adat (circumscriptive kingroups) (Koentjaraningrat, 1992: 114). Berdasarkan dari uraian 
Koentjaraningrat, maka Yos masuk ke dalam kategori kelompok berkorporasi (corporate kingroups) karena Yos merupakan kelompok-kelompok kekerabatan yang jumlah masyarakatnya relatif kecil atau tidak banyak dan mereka masih saling mengenal serta bergaul antar sesamanya.

Desa Pedawa memiliki 14 macam Yos di mana dengan adanya Yos tersebut maka terbentuknya kelas sosial atau kelompok-kelompok sosial dalam masyarakat Desa Pedawa. Menurut Soerjono Soekanto, kelompok sosial adalah himpunan atau kesatuan-kesatuan manusia yang hidup bersama karena saling berhubungan diantara mereka secara timbal balik dan saling mempengaruhi (Belva Hendy Lukmana dan Bambang Wiratsasongko, 2017: 3). Individu-individu memiliki status dan peran yang berbeda-beda itu merupakan pencerminan hak dan kewajiban yang berbeda pula. Seperti contohnya masyarakat yang menyembah atau menyungsung Yos Gunung Agung dan Yos Labuan aji yang memiliki status dan peran yang berbeda. Berdasarkan uraian dan pemaparan yang ada di latar belakang, maka penelitian ini mengetengahkan judul sebagai berikut, "Yos Sebagai Pengintegrasian Masyarakat Desa Pedawa".

Berdasarkan latar belakang di atas, dapat mengedepankan dua pokok permasalahan sebagai berikut: Bagaimana status dan peran anggota masyarakat berdasarkan Yosdi Desa Pedawa, Kecamatan Banjar, Kabupaten Buleleng, Bali ?, Bagaimana implikasi Yos pada struktur sosial masyarakat Desa Pedawa, Kecamatan Banjar, Kabupaten Buleleng, Bali ?

Adapun tujuan yang dicapai dalam penelitian ini adalah sebagai berikut: Untuk mengetahui status dan peran anggota masyarakat berdasarkan Yos, Kecamatan Banjar, Kabupaten Buleleng,
Bali. Untuk mengetahui implikasi Yos pada struktur sosial masyarakat Desa Pedawa, Kecamatan Banjar, Kabupaten Buleleng, Bali.

\section{METODE}

Penelitian ini menggunakan metode penelitian kualitatif.Penelitian kualitatif, informasi yang dikumpulkan dan diolah harus tetap objektif dan tidak dipengaruhi oleh pendapat sendiri.Sedangkan sumber data yang digunakan, yaitu sumber data primer dan sumber data sekunder.

Penelitian ini dilakukan di Desa Pakraman Pedawa, Kecamatan Banjar, Kabupaten Buleleng, Bali.jenis data yang digunakan adalah penelitian kualitatif. Sumber data yang digunakan yaitu sumber data primer yang diperoleh melalui observasi dan wawancara, serta sumber data sekunder yang diperoleh melalui studi pustaka.

\section{HASIL DAN PEMBAHASAN}

\section{Status dan Peran Anggota Masyarakat Berdasarkan Yos di Desa Pedawa}

\section{Asal-usul Yos}

Mengenai sejarah dari asal-usul munculnya Yos di Desa Pedawa, sampai saat ini masyarakat Desa Pedawa tidak memiliki catatan dan tidak ada yang mengetahuinya secara pasti asal-usul adanya Yos adalah berawal dari seseorang yang mengalami kesakitan. Pada saat seseorang tersebut merasa kesakitan, maka mereka akan nunas (meminta) petunjuk dari Ida Bhatara yang melalui balian atau orang pintar, dan setelah dilihat bahwa seseorang tersebut belum memiliki Yos. Dengan tidak memiliki Yos maka seseorang tersebut akan mengalami kesakitan secara terus-menerus. Setelah mempunyai Yos, kesakitan yang dialami orang tersebut akan hilang tanpa diobati. Untuk mencari Yos, maka seseorang harus melakukan 
upacara yang disebut dengan upacara Nedunang Periang. Versi lain mengenai asal-usul Yos yaitu berawal dari seseorang yang datang dari soroh yang berbeda dan memohon perlindungan dan keselamatan ke salah satu dewa yang melinggih di pura yang ada di Desa Pedawa, secara tidak langsung mereka akan menyungsung atau menyembah Yos yang bersemayam atau melinggih di pura tersebut. Seperti misalnya ada seseorang yang datang dari soroh pasek gel-gel ke Pura Munduk Madeg yang ada di Desa Pedawa, di sana mereka memohon perlindungan dan keselamatan, maka secara tidak langsung mereka akan menyungsung atau menyembah Yos munduk madeg. Secara tidak langsung seseorang tersebut menyungsungpasek gel-gel dan Yos yang mereka sungsung adalah Yos munduk madeg.

\section{Yos}

Masyarakat Desa Pedawa mengenal dua kawitan, yaitu kawitan kulit dan kawitan lokal. Kawitan kulit yang terdapat di Desa Pedawa merupakan kawitan atau soroh atau dadia pada umumnya di Bali.Sedangkan, kawitan lokal masyarakat Desa Pedawa menyebut dengan "Yos" yang wajib dimiliki oleh semua masyarakat Desa Pedawa. Yos tersebut terdapat dewa yang sangat dimuliakan dan dewa yang paling dekat dengan masyarakat karena dewa tersebut dipercayai sebagai dewa pelindung. Yos berasal dari kata niosin yang berarti pemujaan atau sungsungan masyarakat mengarah ke dewa tersebut.

\section{a. Perbedaan soroh dengan Yos}

Perbedaan soroh dengan Yos yaitu soroh adalah wiwit asal dari luar atau soroh kawitan yang berasal dari luar atau bisa dikatakan sebagai keturunan kawitan leluhur. Soroh tersebut ada hubungan dengan kawitan pada umumnya di Bali. Soroh di Desa Pedawa biasanya masyarakat menyebut dengan istilah kawitan kulit seperti misalnya soroh atau kawitan kulit Pasek Bendesa Mas dan lain sebagainya. Sedangkan kalau Yos di Desa Pedawa adalah dewa yang disungsung oleh masyarakat serta dewa yang memperhatikan masyarakat. Biasanya masyarakat meminta restu terhadap dewa yang ada di dalam Yos tersebut agar diberi keselamatan dan kesehatan.

\section{b. Upacara Nedunang Periang}

Pelaksanaan upacara keagamaan adalah hal positif untuk melestarikan budaya yang berharga dan bermanfaat untuk mempertahankan identitas suku bangsa. Upacara keagamaan membuktikan kebenaran hakiki darin tatacara dan tradisi yang dimiliki masyarakat (Dzofir, 2017: 6). Masyarakat Desa Pedawa melaksanakan suatu upacara keagamaan bagi mereka yang ingin mendapatkan Yos. Cara untuk mendapatkan Yos tersebut yaitu dengan cara melakukan upacara keagamaan yang disebut dengan upacara Nedunang Periang. Nedunang periang berasal dari kata "nedun" yang berarti turun dan "periang" yang berarti Hyang atau dewa. Upacara nedunang periang adalah upacara yang sudah diberi petunjuk dari Ida Bhatara melalui balian atau orang pintar kemudian orang pintar atau balian tersebut akan kerangsukan dan akan mengatakan bahwa "kamu Yosnya ini karena menurut wahyu kamu Yosnya ini". Dengan adanya petunjuk dari Ida Bhatara melalui balian tersebut, maka seseorang tersebut akan mengetahui Yos apa yang akan disungsungnya.

Upacara nedunang periang dilakukan di sanggah kemulan selama 12 jam dan dilakukan pada waktu malam hari. Dalam pelaksanaan upacara tersebut terdapat pemimpin upacara.Pemimpin upacara tersebut ditentukan oleh anggota keluarga yang melaksanakan upacara. 
Sarana upacara nedunang periang yaitu dengan membuat banten seperti banten pejati atau di Desa Pedawa disebut dengan banten daksina baas pipis canang meraka di sanggah kemulan yang diikuti oleh premas dan anggota keluarga yang ingin mendapatkan Yos. Banten daksina baas pipis canang meraka merupakan banten pokok atau banten utama masyarakat Desa Pedawa.

\section{Macam-macam Yos dan Jaringan Hubungan Diadik dan Diferensialnya}

\section{a. Macam-macam Yos}

Di Desa Pakraman Pedawa memiliki empat belas (14) macam Yos diantaranya ialah: (1) Yos Gunung Agung; (2) Yos Kemulan Bingin; (3) Yos Penyarikan; (4) Yos Bukit Anyar; (5) Yos Labuan Aji; (6) Yos Embang; (7) Yos Munduk Duwur; (8) Yos Kemulan Telaga Waja; (9) Yos Pengempelan; (10) Yos Rambut Siwi; (11) Yos Gadung Gaduh; (12) Yos Muspait; (13) Yos Kemulan Munduk Madeg-Batan Kadap; (14) Yos Batur Mekasa.

\section{b. Jaringan Hubungan Diadik dan Diferensial Yos}

Integrasi adalah pembauran hingga menjadi kesatuan. Hubungan sosial mencerminkan kesatuan-kesatuan kelompok yang didasari hubungan kekerabatan atau garis keturunan (Hendry, dkk, 2013: 3 dan 4). Hubungan diadik penyungsung Yos terjadi pada saat akan berlangsungnya upacara keagamaan di Pura Bingin, seperti sangkep atau rapat anggota masyarakat penyungsung Yos Gunung Agung dengan anggota masyarakat penyungsung Yos Kemulan Bingin mengenai upacara keagamaan di Pura Bingin yang akan dilaksanakan, ngayah di Pura Bingin, dan lain sebagainya. Di sanalah akan terjadi hubungan diadik antara penyungsung Yos Gunung Agung dengan penyungsung Yos
Kemulan Bingin. Hubungan diadik juga terjadi pada saat akan berlangsungnya upacara keagamaan di Pura Munduk Madeg karena di Pura Bingin maupun di Pura Munduk Madeg hanya terdapat dua Yos yang melinggih di pura tersebut. Berbeda halnya dengan Yos yang melinggih atau bersemayam di Pura Desa dan di Pura Telaga Waja. Di sana akan terjadi hubungan diferensial karena masing-masing pura yaitu di Pura Desa maupun di Pura Telaga Waja terdapat lima Yos yang melinggih.

Tata nilai sebagai pengintegrasian di mana masyarakat bersama-sama untuk melakukan persembahyangan dan pemujaan terhadap dewa yang merupakan suatu keyakinan untuk memuja dewa yang melinggih atau bersemayam di dalam Yos tersebut. Aturan-aturan yang mengikat masyarakat penyungsung Yos seperti adanya sangkep atau rapat anggota masyarakat mengenai upacara keagamaan atau perbaikan pura. Adanya suatu Ide-ide atau konsepsikonsepsi tentang hal-hal yang dianggap atau dipandang sangat berharga dalam hidup dan meresapi bagian terpusat dari masyarakat seperti memohon keselamatan dan kesehatan, murah rezeki, ngayah atau mengambil pekerjaan secara sukarela di pura tempat bersemayam atau melinggihnya Yos, saling hormat-menghormati antara penyungsung Yos satu dengan Yoslainnya, hidup rukun, suka bergotong royong, memberikan dana punia atau sumbangan secara sukarela untuk perbaikan pura atau untuk kepentingan di pura tempat melinggih atau bersemayamnya Yos. Tata nilai tersebut merupakan sebuah bentuk sosialisasi untuk menanamkan nilai integrasi sosial kepada masyarakat agar mereka sadar dan memahami bahwa mereka adalah sebuah sistem yang perlu menjunjung tinggi nilai solidaritas sosial di antara anggota masyarakat (Zidni, 2017: 10). 
Status dan Peran Anggota Masyarakat Berdasarkan Yos

Sesungguhnya tidak semua penyungsung Yos memiliki status dan peran di dalam upacara, tetapi hanya beberapa anggota masyarakat saja yang memiliki status dan peran dalam suatu upacara.masyarakat yang menyungsungYos Gunung Agung yang mempunyai status dan peran sebagai balian desa. Balian desa tersebut harus sesuai dengan keturunan.Balian desa adalah seorang yang memiliki wewenang atau kewajiban sebagai pemuput segala upacara dari adat. Kewajiban dari seorang balian desa yaitu sebagai pemuput upacara dari adat atau upacara di pura yang dibantu oleh premas.

Selain status dan peran dari penyungsung Yos gunung, juga terdapat status dan peran dari masyarakat yang menyungsung Yos Labuan Aji. Premas adalah seseorang yang mengempon pura dadia atau sama dengan pemangku pura dadia. Premas memiliki kewajiban yang sama dengan pemangku yaitu membantu Ulu Desa mepinunas atau nganteb balian yang biasa disebut moncol artinya setiap langkah berkaitan dengan parahyangan. Selain mempunyai status dan peran sebagai premas, masyarakat yang menyungsung Yos Labuan Aji juga mempunyai status dan peran sebagai kelian adat.

Di Desa Pedawa juga terdapat status dan peran sebagai janbanguldalam suatu upacara keagamaan.Janbangul adalah orang yang berperan sebagai penghubung manusia dengan dewa yang dilaksanakan dengan cara menghaturkan atau nguningan banten atau sesajen yang dipersembahkan. Penyungsung Yos penyarikan mempunyai status dan peran sebagaisekaa gong.Status dan peran sebagai sekaa gong juga dimiliki oleh penyungsung dari Yos Bukit Anyar dan Yos Embang.
Adanya Yos tersebut maka terbentuknya kelas sosial dalam masyarakat Desa Pedawa. Seperti yang dikemukakan oleh Turner (dalam Morris, 2003: 316 dan 317), bahwa struktur sosial adalah suatu sistem relasi dan status sosial, sebuah pengaturan posisi yang melibatkan institusionalisasi dan pengekalan kelompok dan relasi, sebagai gagasan tentang masyarakat sebagai sistem diferensial dari struktur posisi yang mengisyaratkan hierarki dan eksploitasi. Konsep struktur sosial dalam penelitian ini dipahami sebagai konsep yang membentuk susunan pelapisan dan pola hubungan antara orang-orang yang terikat dalam suatu sistem sosial yang dibatasi atau dikendalikan oleh normanorma atau pola-pola tingkah laku yang disepakati bersama (Qoriah Saleha, 2013: 4). Kelas sosial dalam masyarakat Desa Pedawa berdasarkan Yos dapat dilihat dari posisi atau kedudukan balian desa pada saat upacara keagamaan di pura dimana balian desa wajib menempati posisi paling depan, kemudian diikuti oleh premas-premas, krama ngarep, dan yang terakhir adalah masyarakat Desa Pedawa yang mengikuti upacara keagamaan tersebut.

\section{Implikasi Yos Pada Struktur Sosial Masyarakat Desa Pedawa}

\section{Implikasi Yos}

a. Implikasi Yos Terhadap Kehidupan Dalam Keluarga dan Masyarakat

Implikasi yos terhadap kehidupan dalam keluarga merupakan dampak yang dirasakan secara internal, dimana implikasi ini langsung dirasakan oleh individu maupun oleh keluarganya sebagai orang-orang terdekat.Implikasi dirasakan bagi masyarakat yang tidak mempunyai yos yaitu mereka akan mendapat kendala berupa kesakitan secara terus menerus walaupun mereka berobat itu tidak akan dapat 
menyembuhkan mereka. Setelah memiliki yos maka secara tidak langsung penyakit yang mereka alami akan hilang tanpa diobati. Implikasi tersebut bukan hanya dirasakan atau dialami oleh individu melainkan juga dirasakan atau dialami oleh keluarga terdekat seperti istri, anak, cucu, dan orang-orang terdekat lainnya. Dengan memiliki yos maka kehidupan keluarga akan harmonis dan diberikan kesehatan serta keselamatan oleh dewa yang berstana dalam yos yang mereka sungsung.

Sebagai implikasi eksternal yaitu implikasi terhadap masyarakat yang merupakan implikasi yang tidak langsung. Pada masyarakat Desa Pedawa yang tidak mempunyai yos maka mereka akan mengalami hukum dari segi skala dan niskala. Dari segi skala orang tersebut akan menjadi kecue yaitu istilah lokal dari masyarakat Desa Pedawa yang artinya menjadi buah bibir di lingkungan masyarakat Desa Pedawa, dan dari segi niskala maka orang tersebut akan mengalami kesakitan terus-menerus dalam keluarganya.

\section{b. Implikasi Yos Pada Aspek Sistem Kepercayaan Masyarakat Desa Pedawa}

Pada dasarnya, sistem keyakinan adalah kumpulan konsepsi-konsepsi manusia mengenai dunia gaib dan dunia spiritual yang mengelilinginya. Konsepsi-konsepsi tersebut termasuk dentang dewa-dewa, makhluk halus, kekuatan sakti, dan kesusastraan suci (Pratiwi, 2017: 7). Implikasi yos dapat menimbulkan perasaan yang mendalam terhadap ketulusan hati seseorang saat memuja dewa yang berstana dalam yos tersebut, karena dengan memiliki yos diyakini terhindar dari musibah karena di dalam yos tersebut terdapat dewa yang sangat dimuliakan atau dewa pelindung. Mereka percaya bahwa dewa tersebut akan memberikan perlindungan berupa kesehatan dan keselamatan, maka dari itu masyarakat Desa Pedawa sangat percaya akan adanya yos tersebut. Implikasi yos dalam aspek religi yang ditunjukkan untuk memperkokoh kepercayaan dinamisme yang didasarkan pada keyakinan akan adanya kekuatan gaib.

\section{Makna Yos}

a. Makna Religi

Masyarakat Desa Pedawa melakukan kegiatan sembahyang karena adanya dorongan emosi keagamaan sehingga mereka melakukan kelakuan keagamaan yang menimbulkan makna religius yang tersirat.Makna religius berkaitan dengan aspek keyakinan terhadap kekuatan supranatural yang dipuja di yos tersebut oleh penyungsungnya atau pemujanya.Yos menurut masyarakat Desa Pedawa memiliki kesakralan tersendiri, sehingga setiap masyarakat Desa Pedawa diwajibkan untuk memiliki yos.Oleh karena itu, yos tersebut sangat disakralkan oleh masyarakat Desa Pedawa karena kepercayaan masyarakat Desa Pedawa terhadap hal-hal niskalamembuat mereka sadar bahwa seberapa pentingnya untuk memiliki yos.

\section{b. Makna Sosial}

Pada dasarnya manusia adalah makhluk sosial yang memiliki naluri untuk hidup dengan orang lain. Rasa kebersamaan tampak pula dalam masyarakat Desa Pedawa dalam perilaku ketika bersama dalam keterlibatan mereka mempersiapkan segala keperluan upacara maupun sebuah kegiatan sakral.Yos pada masyarakat Desa Pedawa dapat diinterpretasikan sebagai media membangun kebersamaan untuk memperkuat ikatan sosial.

\section{c. Makna Budaya}

Kebudayaan adalah keseluruhan pengetahuan yang dimiliki masyarakatb mengenai apa yang mereka miliki dan 
rasakan yang dijadikan sebagai sistem penilain terhadap sesuatu yang baik dan buruk. Suatu kebudayaan yang dianggap baik adalah sesuatu yang sesuai dengan ajaran dan harapan dari masyarakat, sedangkan yang dianggap buruk ialah sesuatu yang bertentangan dengan ajaran dan harapan dari suatu masyarakat (Nanda Diah Anindi dan I.B.Gde Pujaastawa, 2018: 6). Makna budaya dari yos tersebut yaitu dilihat dari masyrakat Desa Pedawa yang masih melestarikan yos seperti mempercayai dengan cara memuja atau menyembahnya. Dapat disimpulkan bahwa maknanya adalah tradisi yang mengandung nilai luhur yang merupakan adat kebiasaan yang selalu diyakini secara turun-temurun oleh masyarakat setempat.

\section{SIMPULAN}

Berdasarkan analisis penelitian mengenai Yos sebagai pengintegrasian masyarakat Desa Pedawa, Kecamatan Banjar, Kabupaten Buleleng, Bali dapat dibuat kesimpulan yaitu Masyarakat Desa Pedawa mengenal dua kawitan, yaitu kawitan kulit dan kawitan lokal atau Yos. Terdapat 14 macam Yos. dimana dari macam-macam Yos tersebut terdapat beberapa anggota masyarakat yang memliki status dan peran dalam suatu upacara yaitu sebagai balian desa, permas, kepala desa, janbangul, pedewasan, sekaa gong.implikasi dan makna dari Yos yaitu: implikasi Yos terhadap kehidupan dalam keluarga dan masyarakat, implikasi Yos pada aspek sistem kepercayaan masyarakat desa pedawa, makna religius, makna sosial, dan makna budaya.

\section{REFERENSI}

Andini, Nanda Diah, I.B.Gde Pujaastawa. 2018. Peran Serta Elit Desa dalam Pengembangan Pariwisata di Desa Cempaga Kecamatan Banjar
Kabupaten Buleleng Bali.Prodi Antropologi. Universitas Udayana Volume 22 NO.1.

Ar, Eka Hendry, dkk. 2013. Integrasi Sosial Dalam Masyarakat Multi Etnik. Pontianak: Jurnal STAIN Pontianak Volume 21 No. 1.

Ariawan, Gede Adi Puspa, dkk. 2018. Hukum Adat Kawin Lari Dalam Perspektif UU No.1 Tahun 1974 Tentang Perkawinan (Studi Kasus di Desa Pakraman Pedawa Kecamatan Banjar Kabupaten Buleleng). Singaraja.Jurnal Komunitas Yustisia Universitas Pendidikan Ganesha Jurusan Ilmu Hukum Volume 1 No. 2.

Dzofir, Mohammad. 2017. Agama dan Tradisi Lokal (Studi Atas Pemaknaan Tradisi Rebo Wekasandi Desa Jepang, Mejobo, Kudus). Jawa Tengah: Jurnal IJTIMAIYA Volume 1 No. 01.

Geriya, I Wayan.2000.Transformasi Kebudayaan Bali Memasuki Abad $X X I$. Denpasar: Perusahaan Daerah Provinsi Bali.

Hendrawan, Kadek Andre, Putu Sugi Ardana. 2018. Tinjauan Terhadap Sahnya dan Akibat Hukum Perkawinan Di Bawah Umur Di Desa Pedawa Kecamatan Banjar Kabupaten Buleleng: Jurnal Hukum Unipas Volume 6 No. 1.

Koentjaraningrat.1992. Beberapa Pokok Antropologi Sosial. Jakarta: PT Dian Rakyat.

Lukmana, Belva Hendry, dan Bambang Wiratsasongko. 2017. Hubungan Antara Dukungan Kelompok Sosial Dengan Perilaku Pemilih Pada 
Pemilihan Kepala Daerah Kabupaten Sukoharjo Tahun 2015.Surakarta: Jurnal Sosiologi Universitas Sebelas Maret Surakarta Volume 32 No. 1.

Mayuko, Hara. 2015. "Bentuk Hormat" Dialek Bahasa Bali Aga Dalam Konteks Agama.Jurnal Osaka University Volume 33 No. 2.

Morris, Brian. 2003. Antropologi Agama: Kritik Teori-Teori Agama Kontemporer. Yogyakarta: AK Group.

Pratiwi, Citra Ayu. 2017. Harai: Telaah Konsep Religi Koentjaraningrat. Surabaya.Jurnal Universitas Airlangga Volume 5 No. 2.

Saleha, Qoriah. 2013. Kajian Struktur Sosial dalam Masyarakat Nelayan di Pesisir Kota Balikpapan. BULETIN PSP Volume 21 No. 1.

Sari, Frawita. 2015. Sistem Kekerabatan Sosial Masyarakat dalam Penggunaan Gelar Kebangsawanan "Yang" dam "Abang" di Kota Muntok Kepulauan Bangka (17341816). Jurnal Criksetra. Program Studi Pascasarjana. Universitas Indonesia Volume 4 No. 8.

Yasa, Putu Edy Suryadi, dkk. 2017. Pengelolaan dan Realisasi Dana Peturunan Krama Desa Dalam Pelaksanaan Sabha Di Desa Bali Aga. Singaraja: Program S1 Akuntansi. Universitas Pendidikan Ganesha Volume 07 No. 01.

Zidni.2017. Upacara Adat Kelahiran Sebagai Nilai Sosial Budaya Pada Masyarakat Suku Sasak Desa Pengadangan. Program Studi Pendidikan Sejarah. Universitas Hamzanwadi Volume 2 No. 2. 